\title{
Questions remain about the biolability of dissolved black carbon along the combustion continuum
}

\author{
Sasha Wagner ${ }^{1 凶}$, Alysha I. Coppola ${ }^{2}$, Aron Stubbins (10 ${ }^{3}$, Thorsten Dittmar ${ }^{4,5}$, Jutta Niggemann (10 ${ }^{4}$, \\ Travis W. Drake (10 ${ }^{6}$, Michael Seidel (10 ${ }^{4}$, Robert G. M. Spencer ${ }^{7}$ \& Hongyan Bao ${ }^{8}$
}

ARISING FROM Y. Qi et al. Nature Communications https://doi.org/10.1038/s41467-020-18808-8 (2020).

$\mathrm{T}$ he heating and partial combustion of organic matter produces a continuum of organic compounds ranging from partially altered, biolabile molecules to highly refractory graphite ${ }^{1}$. The apparent biolability of compounds formed at lower charring temperatures $\left(<300^{\circ} \mathrm{C}\right)^{2}$ is akin to the process of humans cooking food to improve digestibility and nutrient absorption. Here, the term biolability refers to carbon fractions with rapid microbial turnover rates (within days to weeks). At high charring temperatures $\left(>450^{\circ} \mathrm{C}\right)$, organic matter can undergo aromatization to form polycondensed and graphitic type structures that resist biodegradation ${ }^{3,4}$. Black carbon (BC) refers to the condensed aromatic fraction of thermally altered biomass that accumulates in carbon reservoirs over thousands of years. This long-lived $\mathrm{BC}$ fraction has become synonymous with refractory organic carbon (OC) and has garnered the most attention in recent years because it shows promise in terms of carbon sequestration and mitigation strategies. After formation, the composition of $\mathrm{BC}$ cycled in aquatic systems is further modulated by hydrophobicity, which governs the partitioning of $\mathrm{BC}$ molecules to the dissolved phase (DBC) $)^{5,6}$. Qi et $\mathrm{al}^{7}$. adapt this definition and describe $\mathrm{BC}$ as a "group of condensed byproduct chemicals," which is consistent with their use of chemothermal oxidation (CTO) to quantify and characterize the thermally stable, residual fraction of $\mathrm{BC}$ that remains after heating. Other analytical approaches, such as the benzenepolycarboxylic acid (BPCA) method, access condensed aromatic fractions of $\mathrm{BC}$ by oxidative chemistry paired with radiocarbon dating rather than inferring thermal stability 8,9 .

Condensed aromatic BC, as measured by the BPCA method, comprises a significant fraction of OC in soils $(14 \%)^{10}$ and of dissolved OC $(D O C)$ in rivers $(2-15 \%)^{11}$ and the ocean $(1-6 \%)^{12,13}$, thus establishing the importance of this refractory carbon pool on a global scale. As BC research has expanded and diversified, so have the methodological approaches used to characterize this thermally altered component of DOC. Radiocarbon $\left(\Delta^{14} \mathrm{C}\right)$ and stable carbon $\left(\delta^{13} \mathrm{C}\right)$ isotopic measurements are increasingly employed to gain insight into potential sources and environmental residence times of DBC across aquatic systems. A simple calculation suggests the global riverine DBC flux (18 Tg-C per year) ${ }^{11}$ could replace the standing stock of oceanic DBC $(14 \mathrm{Pg}-\mathrm{C})^{12}$ in $<800$ years. However, this estimate is at odds with BPCA-specific $\Delta^{14} \mathrm{C}$ measurements, which indicates the residence time of oceanic DBC is $1-2$ orders of magnitude longer ${ }^{12}$. This offset might be explained by petrogenic contributions and/or widespread pre-aging of DBC in soils or other intermediate reservoirs prior to riverine export, but recent research showed riverine $\mathrm{DBC}$ to be heterogeneous in age even within the same catchment ${ }^{14}$. Further adding to this discrepancy is the $\delta^{13} \mathrm{C}$ signatures of oceanic BPCAs, which are significantly ${ }^{13} \mathrm{C}$-enriched compared to global rivers and suggests condensed aromatic DBC may have a marine origin that remains unknown ${ }^{13}$. Isotopic probing of DBC has clearly raised more questions than it has answered. Having conducted an impressive, large-scale effort to quantify and isotopically characterize DBC, Qi et $\mathrm{al}^{7}$. address this conundrum from the CTO analytical perspective.

Similarities between DBC:DOC ratios determined by $\mathrm{CTO}^{7}$ and BPCAs suggest some degree of overlap in DBC captured by the two analytical methods. Isotopic agreement between $\mathrm{DBC}$ and DOC shown by Qi et $\mathrm{al}^{7}$. suggests that CTO-derived DBC is of similar source and bioreactivity as bulk DOC. Although $\delta^{13} \mathrm{C}$ trends mirror those observed by Wagner et al. ${ }^{13}$, similarities between DBC and DOC $\Delta^{14} \mathrm{C}$ values are in opposition to large isotopic offsets described previously for BPCA-derived DBC ${ }^{12,14}$. Given discrepancies in radiocarbon composition between DBC

\footnotetext{
${ }^{1}$ Department of Earth and Environmental Sciences, Rensselaer Polytechnic Institute, Troy, New York, NY, USA. ${ }^{2}$ Geological Institute, Department of Earth Sciences, ETH Zürich, Zürich, Switzerland. ${ }^{3}$ Department of Marine and Environmental Sciences, Civil and Environmental Engineering, and Chemistry and Chemical Biology, Northeastern University, Boston, MA, USA. ${ }^{4}$ Institute for Chemistry and Biology of the Marine Environment (ICBM), University of Oldenburg, Oldenburg, Germany. ${ }^{5}$ Helmholtz Institute for Functional Marine Biodiversity (HIFMB) at the University of Oldenburg, Oldenburg, Germany. ${ }^{6}$ Department of Environmental Systems Science, ETH Zurich, Zurich, Switzerland. ${ }^{7}$ Department of Earth, Ocean, and Atmospheric Science, Florida State University, Tallahassee, FL, USA. ${ }^{8}$ State Key Laboratory of Marine Environmental Science, College of Ocean and Earth Sciences, Xiamen University, Xiamen, China. ${ }^{凶}$ email: wagnes3@rpi.edu
} 
isolated by CTO and BPCA methods, the measurement of DOC and $\mathrm{BC}$ standards ${ }^{15}$ is recommended to allow more informed intercomparisons of $\mathrm{CTO}$ and $\mathrm{BPCA}$-derived $\mathrm{DBC}$ reactivities and residence times. A comparative isotopic assessment of $\mathrm{BC}$ standards via CTO would also alleviate or clarify concerns regarding analytical artifacts associated with the method. For example, the accidental transformation of sugars to $\mathrm{BC}$ during the CTO heating step has indicated the technique is prone to false positives $^{16}$. However, Qi et $\mathrm{al}^{7}$. did attempt to rule out the possibility of false positives under their CTO methodological conditions, stating that they "did not detect any measurable DBC converted from fresh DOC" that was derived from fresh marsh plants and coastal phytoplankton.

Qi et $\mathrm{al}^{7}$. ascribe the aging (i.e., ${ }^{14} \mathrm{C}$-depletion) of $\mathrm{DBC}$ along the land-to-ocean continuum to in situ biodegradation of the CTO-derived fraction of condensed aromatic carbon. To test the biolability of $\mathrm{DBC}$, the authors carry out a biodegradation experiment, in which bulk DOC is leached from wood charcoal and exposed to microbial activity simultaneously. The biodegradation observed for charcoal-leached DOC is then used to justify the presumed biolability of CTO-derived DBC in rivers. The approach taken by Qi et $\mathrm{al}^{7}$. to investigate $\mathrm{DBC}$ biolability leads to three concerns: First, the authors conducted leaching and biodegradation experiments at the same time, which precludes any direct assessment of DBC biolability. Under the described experimental conditions, it is impossible to disentangle leaching versus biodegradation processes. Second, the apparent lack of replication raises questions about the repeatability and scalability of their results. Previous research has demonstrated extreme heterogeneity for different types of charcoal leachates, in terms of both carbon yield and composition ${ }^{5,6}$. Therefore, it is unknown how representative the wood charcoal selected by Qi et $\mathrm{al}^{7}$. is of charcoal-derived DOC or DBC entering aquatic systems on larger scales. Third, and perhaps most importantly, Qi et $\mathrm{al}^{7}$. conflate the understanding of what is molecularly represented by the DBC window with that of the entire combustion continuum. The former is a subset of the latter (Fig. 1). The full suite of DOC molecules leached by charcoal include materials that have a very different set of physicochemical characteristics and biological reactivities than what has been observed for the condensed aromatic DBC fraction. Charcoal leachates contain an abundance of polar functional groups and low molecular weight organic species that facilitate high microbial turnover rates ${ }^{17,18}$. The fact that dehydrated carbohydrates (anhydrosugars) and other small, soluble molecules are abundant in charcoal leachate does not mean that this fraction of released DOC is DBC. Said another way, these biolabile molecules are indeed part of the thermally altered byproducts of biomass combustion, but not part of the condensed aromatic compound class targeted using BC analytical techniques (e.g., BPCA and CTO methods). In fact, a recent experimental study has shown that the BPCA-derived $\mathrm{DBC}$ fraction of charcoal leachates is highly resistant to microbial

\section{COMBUSTION CONTINUUM}
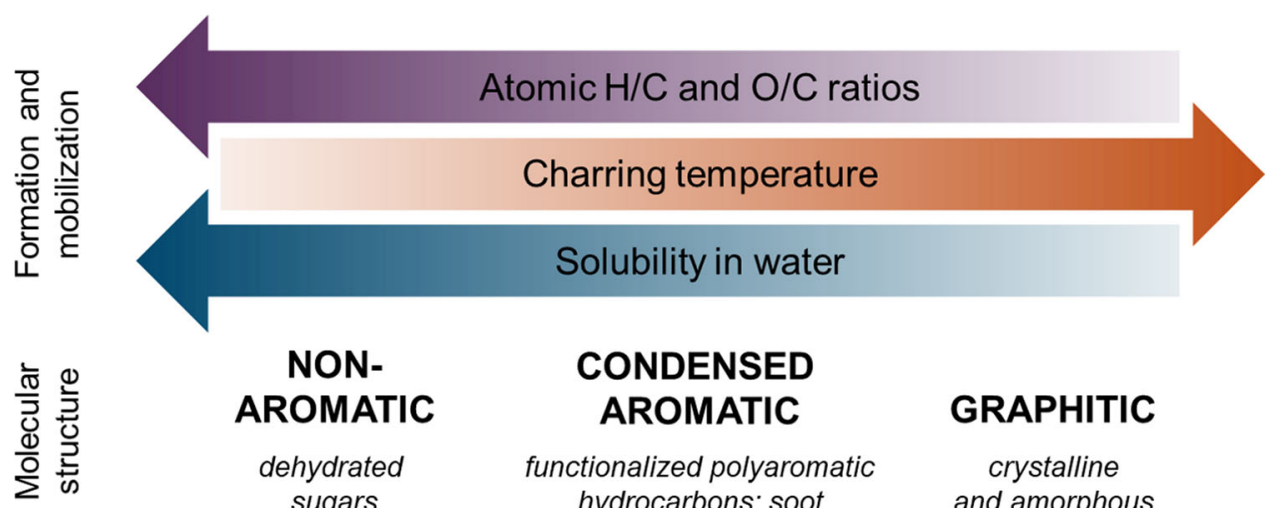

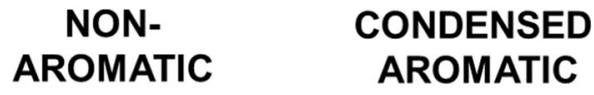

dehydrated sugars

functionalized polyaromatic hydrocarbons; soot

\section{GRAPHITIC}

crystalline and amorphous

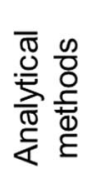

Levoglucosan

BPCAs

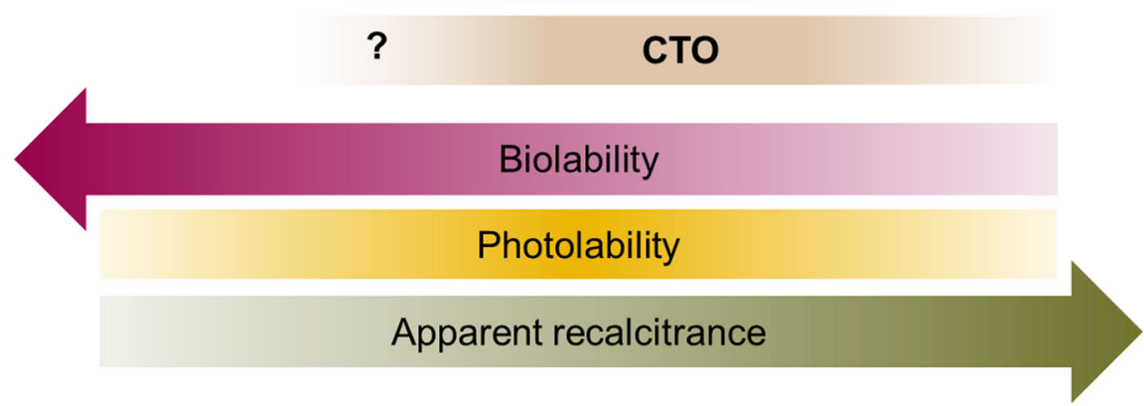

Fig. 1 The theoretical combustion continuum. The combustion continuum ranges from mildly thermally altered biomolecules to highly condensed and graphitic structures and describes the formation, composition, and reactivity of different carbon fractions. Arrows indicate the direction of increase. Peak photolability is expected for the condensed aromatic fraction of dissolved black carbon (DBC). The presumed analytical windows for levoglucosan, benzenepolycarboxylic acid (BPCAs), and chemothermal oxidation (CTO) methods are also shown. Data in Qi et al. (2020) suggest CTO captures more than just graphitic DBC, therefore we have expanded the range for this method and included a question mark to denote that further research is needed to understand the breadth of this DBC fraction. 
degradation ${ }^{4}$. Therefore, the authors' key finding that biodegradation is the likely mechanism for losses of CTO-derived DBC during transit is unfounded. Further research is required to fully assess the biolability of the various pyrogenic subcomponents by measuring losses of CTO-derived, BPCA-derived, and other fractions of DBC directly.

DBC is operationally defined by the method used to quantify and characterize it. When introducing their study, Qi et $\mathrm{al}^{7}$. clearly defined $\mathrm{DBC}$ as the thermally resistant fraction recovered by the CTO method. However, this definition was not kept consistent when describing the results of the biodegradation experiment, in which "all organic compounds dissolved from the biochar were treated as DBC." This is an honest statement of an assumption that is too simplistic, which led to what is probably an erroneous overestimate of $\mathrm{DBC}$ loss from biodegradation during riverine transit. The combustion continuum describes a complex and heterogenous mixture of all OC (including BC) that is derived from heating, thus its apparent biolability is an emergent property that varies with both composition and environmental conditions (Fig. 1). Published research that investigates the biogeochemical processing of thermally altered organic matter should make this point obvious and clearly define the analytical window through which DBC is being viewed. Although the research community is still working to define the structural edges of each method's analytical window, we have a good sense of where different methods sit along the combustion continuum (Fig. 1). Since we cannot offer objective structural terms for each segment of the combustion continuum at present, we recommend that authors be explicit in stating the range of chemical structures their chosen method is presumed to capture when describing research findings. Furthermore, if two or more methods are employed in the same study, then unique monikers should be applied (e.g., bulk DOC, $\mathrm{DBC}_{\text {Сто, }}$ $\mathrm{DBC}_{\mathrm{BPCA}}$ ) when describing results of carbon-based methods to avoid misleading readers. Our recommendations aim to promote more accurate comparisons of DBC-specific reactivities and the reactivity of thermally altered material more broadly. In doing so, we can bring meaningful biogeochemical context to the environmental trends observed.

Nomenclature describing BC has evolved alongside the methods we use to characterize this critical carbon fraction and definitions vary among scientific disciplines. For example, atmospheric communities describe BC as light-absorbing, sootlike aerosols, whereas soil scientists describe $\mathrm{BC}$ as the carbonaceous (carbon-rich) material that resists degradation in soils and sediments ${ }^{19}$. In the aquatic biogeochemistry community, pyrogenic carbon $(\mathrm{PyC})$ refers to the entire continuum of molecules formed from fire and the term is often used to contextualize the condensed aromatic $\mathrm{BC}$ fraction. The term thermogenic carbon may also apply to $\mathrm{BC}$, as it is used to describe organic matter that has been thermally altered by non-fire processes (e.g., geologic maturation, hydrothermal circulation). Since the use of specific scientific language promotes efficient communication within and among disciplines, we emphasize the use of clear and consistent definitions to describe BC. Thus, analytical windows must always be precisely articulated to avoid the confusion that results from propagation of poorly defined terminology. From an analytical perspective, it is also essential that the DBC community works together to establish consistency when reporting DBCspecific isotopic signatures. Specifically, a cross-laboratory comparison that incorporates multiple methods measuring $\mathrm{BC}$ reference materials ${ }^{15}$ is necessary to establish direct linkages between DBC reactivity and isotopic composition $\left(\Delta^{14} \mathrm{C}\right.$ and $\delta^{13} \mathrm{C}$ ). Clear and transparent corrections for radiocarbon data are also mandatory when reporting $\mathrm{DBC} \Delta{ }^{14} \mathrm{C}$ composition, because extensive processing of DBC data can drastically alter $\Delta^{14} \mathrm{C}$ values $^{9,20}$. Since a universal method that covers the entire combustion continuum does not exist, we rely on a suite of methods to examine the complexity of thermally altered carbon, each capturing a different compositional and reactivity fraction (Fig. 1). By following the recommendations described here, we can best contribute to the global initiative to constrain DBC sources and fate along the land-to-ocean continuum.

\section{Data availability}

No datasets were generated for this manuscript.

Received: 2 November 2020; Accepted: 14 June 2021; Published online: 13 July 2021

\section{References}

1. Masiello, C. A. New directions in black carbon organic geochemistry. Mar. Chem. 92, 201-213 (2004).

2. Kuo, L. J., Louchouarn, P. \& Herbert, B. E. Influence of combustion conditions on yields of solvent-extractable anhydrosugars and lignin phenols in chars: implications for characterizations of biomass combustion residues. Chemosphere 85, 797-805 (2011).

3. Kuzyakov, Y., Bogomolova, I. \& Glaser, B. Biochar stability in soil: Decomposition during eight years and transformation as assessed by compound-specific ${ }^{14} \mathrm{C}$ analysis. Soil Biol. Biogeochem. 70, 229-236 (2014).

4. Bostick, K.W., Zimmerman, A.R., Goranov, A.I., Mitra, S., Hatcher, P.G., \& Wozniak, A.S. Biolability of fresh and photodegraded pyrogenic dissolved organic matter from laboratory-prepared chars. JGR: Biogeosci. 126, e2020JG005981 (2021).

5. Wagner, S., Ding, Y. \& Jaffé, R. A new perspective on the apparent solubility of dissolved black carbon. Front. Earth Sci. 5, 75 (2017).

6. Wozniak, A. S. et al. Molecular heterogeneity in pyrogenic dissolved organic matter from a thermal series of oak and grass chars. Org. Geochem. 148, 104065 (2020).

7. Qi, Y. et al. Dissolved black carbon is not likely a significant refractory organic carbon pool in rivers and oceans. Nat. Commun. 11, 5051 (2020).

8. Dittmar, T. The molecular level determination of black carbon in marine dissolved organic matter. Org. Geochem. 39, 396-407 (2008).

9. Coppola, A. I., Ziolkowski, L. A. \& Druffel, E. R. M. Extraneous carbon assessments in radiocarbon measurements of black carbon in environmental matrices. Radiocarbon 55, 1631-1640 (2013).

10. Reisser, M., Purves, R. S., Schmidt, M. W. I. \& Abiven, S. Pyrogenic carbon in soils: a literature-based inventory and a global estimation of its content in soil organic carbon and stocks. Front. Earth Sci. 4, https://doi.org/10.3389/feart.2016.00080 (2016).

11. Jones, M. W. et al. Fires prime terrestrial organic carbon for riverine export to the global oceans. Nat. Commun. 11, 2791 (2020).

12. Coppola, A. I. \& Druffel, E. R. M. Cycling of black carbon in the ocean. Geophys. Res. Lett. 43, 4477-4482 (2016).

13. Wagner, S. et al. Isotopic composition of oceanic dissolved black carbon reveals non-riverine source. Nat. Commun. 10, 5064 (2019).

14. Coppola, A. I. et al. Marked isotopic variability within and between the Amazon River and marine dissolved black carbon pools. Nat. Commun. 10, https://doi.org/10.1038/s41467-019-11543-9 (2019).

15. Hammes, K. et al. Comparison of quantification methods to measure firederived (black/elemental) carbon in soils and sediments using reference materials from soil, water, sediment and the atmosphere. Glob. Biogeochem. Cy. 21, GB3016 (2007).

16. Gelinas, Y., Prentice, K., Baldock, J. \& Hedges, J. An improved thermal oxidation method for the quantification of soot/graphitic black carbon in sediments and soils. Env. Sci. Technol. 35, 3519-3525 (2001).

17. Norwood, M., Louchouarn, P. \& Kuo, L.-J. Harvey O.R. Characterization and biodegradation of water-soluble organic matter extracted form lowtemperature charcoals. Org. Geochem. 56, 111-119 (2013).

18. Myers-Pigg, A. N. et al. Labile pyrogenic dissolved organic carbon in major Siberian Arctic rivers: Implications for wildfire-stream metabolic linkages. Geophys. Res. Lett. 42, 377-385 (2015).

19. Hammes, K. \& Abiven, S. in Fire Phenomena and the Earth System: An Interdisciplinary Guide to Fire Science (ed. Belcher, C. M.) 157-176. (John Wiley \& Sons, Inc., 2013).

20. Hanke, U. M. et al. Comprehensive radiocarbon analysis of benzene polycarboxylic acids (BPCAs) derived from pyrogenic carbon in environmental samples. Radiocarbon 59, 1103-1116 (2017). 


\section{Acknowledgements}

This work was supported by the National Science Foundation (OCE \#2017577 awarded to SW and AS). AIC acknowledges support from the Swiss National Science

Foundation (\#PZ00P2_185835)

\section{Author contributions}

S.W. led in writing the manuscript with substantial input and contributions from A.I.C. A.S., T.D., J.N., T.W.D., M.S., R.G.M.S., and H.B.

\section{Competing interests}

The authors declare no competing interests.

\section{Additional information}

Correspondence and requests for materials should be addressed to S.W.

Reprints and permission information is available at http://www.nature.com/reprints
Publisher's note Springer Nature remains neutral with regard to jurisdictional claims in published maps and institutional affiliations.

\section{(c) (1)}

Open Access This article is licensed under a Creative Commons Attribution 4.0 International License, which permits use, sharing, adaptation, distribution and reproduction in any medium or format, as long as you give appropriate credit to the original author(s) and the source, provide a link to the Creative Commons license, and indicate if changes were made. The images or other third party material in this article are included in the article's Creative Commons license, unless indicated otherwise in a credit line to the material. If material is not included in the article's Creative Commons license and your intended use is not permitted by statutory regulation or exceeds the permitted use, you will need to obtain permission directly from the copyright holder. To view a copy of this license, visit http://creativecommons.org/licenses/by/4.0/.

(c) The Author(s) 2021 